\title{
Letter
}

Subscriber access provided by King Abdullah University of Science and Technology Library

\section{Exploiting Confinement Effects to Tune Selectivity in Cyclooctane Metathesis}

\author{
Eva Pump, Zhen Cao, Manoja K Samantaray, Anissa \\ Bendjeriou-Sedjerari, Luigi Cavallo, and Jean-Marie Basset
}

ACS Catal., Just Accepted Manuscript • DOI: 10.1021/acscatal.7b01249 • Publication Date (Web): 24 Aug 2017

Downloaded from http://pubs.acs.org on August 28, 2017

\section{Just Accepted}

"Just Accepted" manuscripts have been peer-reviewed and accepted for publication. They are posted online prior to technical editing, formatting for publication and author proofing. The American Chemical Society provides "Just Accepted" as a free service to the research community to expedite the dissemination of scientific material as soon as possible after acceptance. "Just Accepted" manuscripts appear in full in PDF format accompanied by an HTML abstract. "Just Accepted" manuscripts have been fully peer reviewed, but should not be considered the official version of record. They are accessible to all readers and citable by the Digital Object Identifier (DOI®). "Just Accepted" is an optional service offered to authors. Therefore, the "Just Accepted" Web site may not include all articles that will be published in the journal. After a manuscript is technically edited and formatted, it will be removed from the "Just Accepted" Web site and published as an ASAP article. Note that technical editing may introduce minor changes to the manuscript text and/or graphics which could affect content, and all legal disclaimers and ethical guidelines that apply to the journal pertain. ACS cannot be held responsible for errors or consequences arising from the use of information contained in these "Just Accepted" manuscripts. 
Confinement effects ${ }^{1-4}$ have been invoked in heterogeneous catalysis to improve the selectivity (e.g. asymmetric synthesis, ${ }^{4-5}$ hydrocarbon cracking, ${ }^{6-8}$ methanol to olefin conversion ${ }^{9}$ ) by using nanostructured catalysts. A confinement effect has also been described in olefin metathesis of cyclic olefins using mesoporous supported catalysts: ${ }^{10}$ In cyclooctene metathesis, depending on the pore sizes of the supported catalysts, more polymeric (large pores) or more cyclic, oligomeric (dimers, trimers and tetramers) products were found. Alkane metathesis, ${ }^{11-13}$ which includes an olefin metathesis step in its mechanism, ${ }^{11-14}$ seems to be another attractive reaction to improve selectivity by exploiting confinement effects. The main difference between both reactions (olefin and alkane metathesis) is the dehydrogenation/hydrogenation steps which occurs in alkane metathesis before and after the olefin metathesis step and converts alkane into alkene and, after olefin metathesis, the newformed alkene back into alkanes. ${ }^{11}$ A broad product distribution is typically found in alkane metathesis using a multifunctional surface organometallic chemistry (SOMC) catalysts suggesting that, besides the abovementioned steps, another side reaction occurs, namely double bond migration (DBM) ${ }^{14}$ which led us to call metathesis of alkanes "isometathesis of alkanes". Its competition with ring opening metathesis (ROM) and ring closing metathesis (RCM) leads to the formation of higher and lower analogues of the starting alkane. ${ }^{15-16}$ Previously, cyclooctane $\left(c \mathrm{C}_{8}\right)$ metathesis, using the surface organometallic fragment (SOMF) [( $\left.\left.\equiv \mathrm{SiO}^{-}\right) \mathrm{WMe}_{5}\right]$ A, immobilized on silica nanoparticles (Ao) was shown to give mainly ring contracted products as cyclopentane, cyclohexane and cycloheptane $\left(c \mathrm{C}_{5}, c \mathrm{C}_{6}\right.$, $\left.c \mathrm{C}_{7}\right)$ and dimeric cyclohexadecane $\left(c \mathrm{C}_{16}\right)$ as a secondary product. ${ }^{15}$ By applying the confinement strategy for the same reaction, an improved selectivity towards the dimer $c \mathrm{C}_{16}$ was obtained using small pore sizes, while mainly ring contracted products $\left(c \mathrm{C}_{5}-c \mathrm{C}_{7}\right)$ were detected using larger pore sizes. This unexpected results is explained by theoretical modeling demonstrating that the effective volume and the shape (Sterimol parameter) ${ }^{17-18}$ of the main intermediates (metallacycles) play a critical role in orienting the reaction toward dimerization (ROM/RCM) or ring contraction (ROM/DBM/RCM).

Typically, materials are prepared through the SOMC19-20 approach allowing well-defined catalyst supported on silica, ${ }^{21-23}$ alumina ${ }^{24}$ or silica-alumina. ${ }^{16,25}$ To be in line with the concept of "Catalysis by Design", ${ }^{26}$ several physical parameters of the support need to be considered, as pore size and structure, aggregation properties and particle size. Herein, we focus on tuning the pore size of the mesoporous silica support (SBA15 and MCM41 having the same hexagonal structure, but different pore diameters $\left[d_{\text {pore }}=60 \AA\right.$ (1), $30 \AA$ (2) and $25 \AA$ (3)]). ${ }^{27-29}$ In any of these systems we found a similar, very broad distribution of particle size (between 200-1000 nm). Subsequently, $\mathrm{WMe}_{6}$ was immobilized on $\mathbf{1}, \mathbf{2}$ and $\mathbf{3}$ to form [ $\left.\left(\equiv \mathrm{SiO}_{-}\right) \mathrm{WMe}_{5}\right] \mathbf{A}$ inside the mesopores. ${ }^{22}$ The mesoporous support was treated at $500^{\circ} \mathrm{C}$ under high vacuum $\left(10^{-5} \mathrm{mbar}\right)$ which is the maximum temperature which can be applied to prevent MCM-41 from collapsing ${ }^{30}$ and the minimum temperature to obtain 
isolated silanols $(\equiv \mathrm{SiOH})^{31}$. It is noteworthy that the thermal treatment of mesoporous material induce the disappearance of the micropores which do not affect the catalytic results (Table $\mathrm{S} 1, \mathrm{ESI}+$ ). The successful grafting of $\mathrm{WMe}_{6}$ inside the mesopores forming A1, A2 and $\mathbf{A}_{3}$ was shown previously ${ }^{22}$ by $\mathrm{N}_{2}$ sorption, TEM (Figure $\mathrm{S}_{1}$ and $\mathrm{S}_{2}$, $\mathrm{ESI} \dagger$ ) and dynamic nuclear polarization surface enhanced NMR spectroscopy (DNP-SENS). Catalysts A1, A2 and A3 were tested in $c C_{8}$ metathesis and compared with results obtained with catalyst Ao' ${ }^{15}$ (Figure 1). Promising trends were obtained regarding the selectivity towards the desired product $c \mathrm{C}_{16}$ : When considering all formed products, the selectivity for $c \mathrm{C}_{16}$ increases with decreasing $d_{\text {pore }}$ of MSNs.
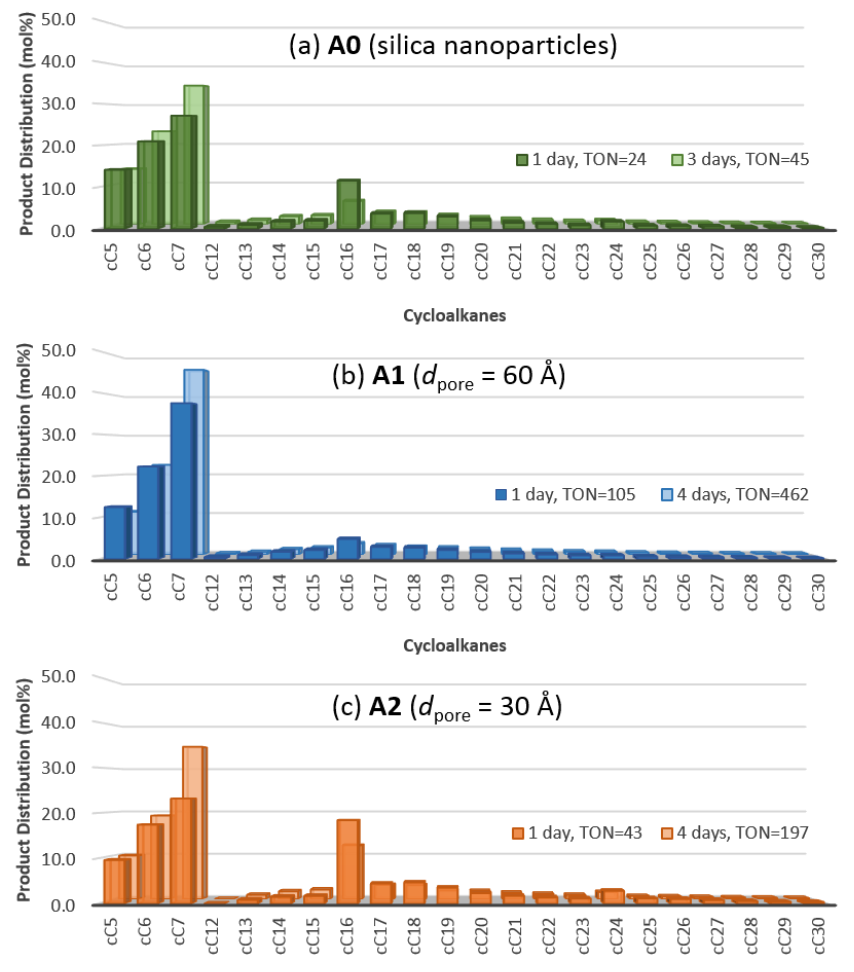

Cycloalkanes

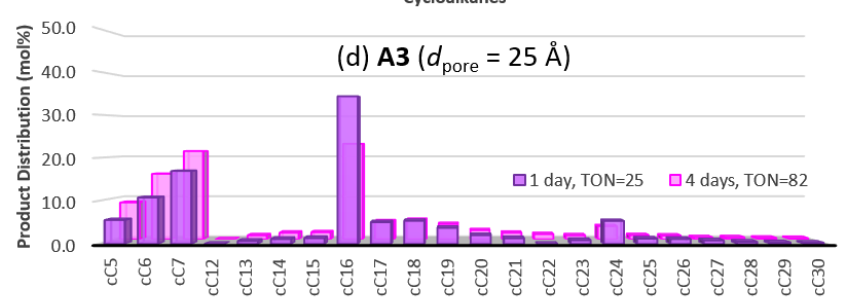

Cycloalkanes

Figure 1. Product distributions of $c \mathrm{C}_{8}(3.7 \mathrm{mmol}(\mathbf{A 0})$ and 7.4 mmol (A1, A2, A3)) metathesis at $150^{\circ} \mathrm{C}$ (batch reactor) after 1 (front) and 3-4 days (back) catalyzed by $\mathbf{A}$ bearing different supports. (a) A0: silica nanoparticles, $d_{\text {particle }}=120 \AA$, [W]: $6.5 \mu \mathrm{mol} ;{ }^{15}$, 32 (b) A1: SBA15, $d_{\text {pore }}=60 \AA$, [W]: $12.4 \mu \mathrm{mol}$; (c) A2: MCM41, $d_{\text {pore }}=30 \AA$, [W]: $14.8 \mu \mathrm{mol}$; (d) A3: MCM41, $d_{\text {pore }}=25 \AA$, [W]: $8.7 \mu \mathrm{mol}$.

After one day, A1 (with the largest pore diameter) produces only $5 \%$ of $\mathrm{cC}_{16}$, while $\mathbf{A 2}$ yields $18 \%$ and $\mathbf{A}_{3}$ even $34 \%$ of $c \mathrm{C}_{16}$. Contrary, the sum of the ring contracted products $\left[\Sigma\left(c \mathrm{C}_{5}, c \mathrm{C}_{6}, c \mathrm{C}_{7}\right)\right]$ decreases in the same order from $63 \%$, to
$50 \%$ and 34\%, respectively. After four days, the selectivity for $c \mathrm{C}_{16}$ decreases in all cases by up to $40 \%$ ending up with 3\% (A1), 12\% (A2) and 23\% (A3) of $c \mathrm{C}_{16}$. Nevertheless, the selectivity for the dimer $c C_{16}$ is maintained using $A_{3}$ (23\%), and was found to be the main product after 4 days. It is noteworthy to mention that catalyst Ao presents a better selectivity towards $c C_{16}$ compared to $\mathrm{Ar}$ (12\% vs. 5\%), but a decreased selectivity as $\mathbf{A 2}$ and $\mathbf{A} 3$ (18\%, 34\%, respectively, vs. $12 \%)$. The most suitable explanation for this result is the aggregation of silica nanoparticles in non-polar solvent 33 (as $c C_{8}$ ) which probably creates interparticular spaces between the nanoparticles evoking a similar confinement effect for Ao as found for A2 and A3, however less pronounced (Figure $\mathrm{S}_{3}$, ESI $\dagger$ ). The fact that selectivity towards the dimer $c \mathrm{C}_{16}$ can be improved with Ao when the reaction is not stirred further supports this indication. ${ }^{15}$ It is known that the confinement strategy is affected by (i) the low accessibility of the active sites and (ii) a hindered diffusion of the substrate or product inside the mesopores. ${ }^{2}$ Hence, it is not surprising that also the TONs of A1, A2 and $\mathbf{A}_{3}$ (after 1 day) drop from 105 to 42 and 25, respectively, when reducing the mesoporous diameter from 6o (A1) to $30(\mathbf{A 2})$ and $25 \AA$ ( $\left.\mathbf{A}_{3}\right)$.

The most crucial steps of the transformation of $c \mathrm{C}_{8}$ catalyzed by $\mathbf{A}$ are the dehydrogenation (I), olefin metathesis (II) and hydrogenation (III) and were explained in previous work. ${ }^{12,15}$ It was reported that thermal activation of $\mathbf{A}$, involves an intramolecular $\mathrm{CH}$-activation by releasing two methane molecules, forming $\left[(\equiv \mathrm{SiO}-) \mathrm{W}(\equiv \mathrm{CH}) \mathrm{Me}_{2}\right] \mathbf{B}^{21}$ DFT calculations of the activation mechanism (Figure $\mathrm{S}_{7}$ S9, ESI+) indicate a $\mathrm{CH}$-activation of cyclooctane with the $\mathrm{W}(\equiv \mathrm{CH})$ triple bond (Figure 2a) forming $[(\equiv \mathrm{SiO}$ ) $\left.\mathrm{W}\left(=\mathrm{CH}_{2}\right)(\mathrm{Me})_{2}\left(c \mathrm{C}_{8}\right)\right]$ C. A subsequent $\beta-\mathrm{H}$ elimination and decoordination of the formed olefin leads to the active site $\left[(\equiv \mathrm{SiO}-) \mathrm{W}\left(=\mathrm{CH}_{2}\right)(\mathrm{Me})_{2}(\mathrm{H})\right] \quad$ D. ${ }^{34}$ Other activation pathways (including the tautomer of $\mathbf{B},[(\equiv \mathrm{SiO}-$ ) $\left.\left.\mathrm{W}\left(=\mathrm{CH}_{2}\right)_{2} \mathrm{Me}\right] \mathbf{B}_{2}\right) 35$ are excluded as the energy barriers for the rate determining step ( $\mathrm{CH}$-bond activation) clearly exceed the one of the proposed activation mechanism by at least around $10 \mathrm{kcal} / \mathrm{mol}$ (Figure S8, ESI†).

The initial steps of $c \mathrm{C}_{8}$ metathesis (common for $c \mathrm{C}_{7^{-}}$, $c \mathrm{C}_{8^{-}}, c \mathrm{C}_{9^{-}}$and $c \mathrm{C}_{16}$-pathways) were reported previously. ${ }^{15}$ For the sake of readability, we briefly recapitulate the main conclusions for $c \mathrm{C}_{8}$ (Figure $2 \mathrm{~b}$ ). (i) $\mathrm{CH}$-activation with $\mathrm{cC}_{8}$ and the active species $\mathbf{D}$ releases hydrogen and forms $\mathbf{C}$. (ii) $\beta-\mathrm{H}$ elimination of the cyclooctyl-ligand leads to the coordination intermediate $\mathbf{E}$. (iii) The coordinated cyclooctene reacts with the $[\mathrm{W}]=\mathrm{CH}_{2}$ moiety forming metallacycle F. (iv) A subsequent opening of the metallacycle leads to the coordination intermediate G. (v) Decoordination of the double bond leads to the open $[(\equiv \mathrm{SiO}-$ )W(=nonenylidene $)_{2} \mathrm{Me}$ ] intermediate o. (vi) A subsequent $\mathrm{CH}$-activation with another $c \mathrm{C}_{8}$ leads to 1 (Figure S9, ESI), which is the actual starting point of this theoretical study. The dimer $c \mathrm{C}_{16}$ is generated from $\mathbf{1}$ through $\beta$-H-elimination and a successive ROM and RCM of the internal and terminal double bond (1-9, Figure 2c). The formation of ring contracted products (and other products containing a carbon number other than a multiple of 8 ) is explained by 
(a)
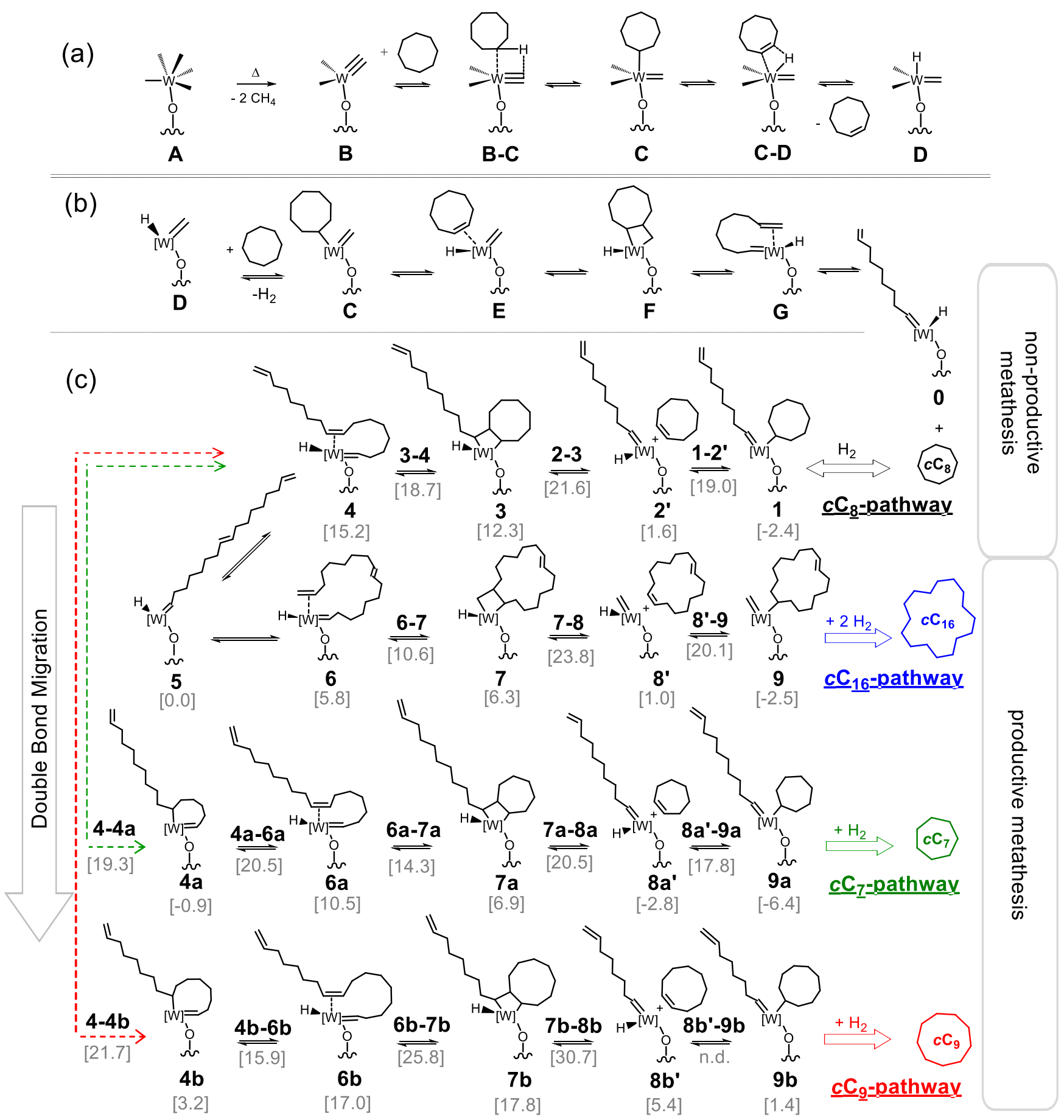

Figure 2. (a) Formation of active species $\left[(\equiv \mathrm{SiO}-) \mathrm{W}\left(=\mathrm{CH}_{2}\right) \mathrm{Me}_{2} \mathrm{H}\right] \mathbf{D}$ from pre-catalyst $[(\equiv \mathrm{SiO}-) \mathrm{WMe} 5]$ A through intermediates $[(\equiv \mathrm{SiO}$ ) $\left.\mathrm{W}(\equiv \mathrm{CH}) \mathrm{Me}_{2}\right] \mathbf{B}$ (experimentally observed) and $\left[(\equiv \mathrm{SiO}-) \mathrm{W}(=\mathrm{CH})\left(c \mathrm{C}_{8}\right) \mathrm{Me}_{2}\right] \mathbf{C}$ and concomitant transition states B-C and C-D. (b) Initial steps of $c \mathrm{C}_{8}$ metathesis, illustrating the formation of $\mathbf{1}$ starting from the active site $\left[(\equiv \mathrm{SiO}-) \mathrm{W}\left(=\mathrm{CH}_{2}\right) \mathrm{Me}_{2} \mathrm{H}\right] \mathbf{D}$ through $\mathrm{CH}$-activation by $\sigma$ bond metathesis of $c \mathrm{C}_{8}$ and ring opening metathesis (ROM) through intermediates $\mathbf{C}, \mathbf{E}, \mathbf{F}, \mathbf{G}$, and $\mathbf{H}$. (c) Ring-opening-ring closing metathesis (ROM-RCM) for $c \mathrm{C}_{8}(\mathbf{1 - 5})$ metathesis leading to $c \mathrm{C}_{16}(\mathbf{5 - 9})$ and to $c \mathrm{C}_{7}(4-9 \mathrm{a})$ and $c \mathrm{C}_{9}(\mathbf{4 - 9})$ through a preceding double bond migration. The bold numbers indicate the labeling of the intermediates and transition states, the [grey] numbers in parenthesis represent the free energies $(\Delta \mathrm{G})$ in $\mathrm{kcal} / \mathrm{mol}$, which were determined by DFT calculations (M06/TZVP//BP86/SVP, pcm=cyclohexane, $\mathrm{P}=1354 \mathrm{~atm})$.

a concurring DBM in intermediate $\mathbf{4}$ (towards $\mathbf{4}$ a or $\mathbf{4} \mathbf{b}$, Figure 2c). The occurrence of a chain walking process is already known in alkane metathesis ${ }^{14}$ and proceeds via the simple insertion of the double bond into the $\mathrm{W}-\mathrm{H}$ bond followed by $\beta-\mathrm{H}$ elimination. The mechanism of ROM$\mathrm{RCM}\left(c \mathrm{C}_{8}\right.$-pathway, $c \mathrm{C}_{16}$-pathway) and ROM-DBM-RCM $\left(c \mathrm{C}_{7}\right.$-pathway, $c \mathrm{C}_{9}$-pathway) are summarized in Figure $2 \mathrm{c}$ and Figure S11, S12 and S13, in ESI†. The final alkane will be generated through stepwise hydrogenation of the new olefin (costs approximately $15 \mathrm{kcal} / \mathrm{mol}$ ), which can be achieved with only a small steady state concentration of $\mathrm{H}_{2}{ }^{34}$ (Figure S9, ESI $\dagger$ ). Herein, we focus on the competition 
between olefin metathesis and DBM steps. The key steps of the respective pathways are discussed using intermediate 5 as reference structure at $0.0 \mathrm{kcal} / \mathrm{mol}$. To rationalize the formation of $c \mathrm{C}_{16}$, the respective reaction pathway $\left(c \mathrm{C}_{16}\right.$-pathway in Figure $2 c$ and Figure $\left.\mathrm{S} 11, \mathrm{ESI}+\right)$ was investigated. The most important observations are highlighted in the following. (i) Intramolecular coordination (back biting) of the terminal double bond (leading from 5 to 6 ) is more favorable than coordination of the internal double bond (from 5 to 4 ) by roughly $10 \mathrm{kcal} / \mathrm{mol}$. (ii) Comparing the opening step of the metallacycles 3 (leading to 2 ) and 7 (leading to 8), we found that the disubstituted tungstacyclobutane complex 7 is more stable towards the loss of the olefin than the trisubstituted tungstacyclobutane complex 3, presumably for steric reasons (the metallacycle of 7 is disubstituted whereas the metallacycle 3 is trisubstituted and we found this difference to be crucial in the stereochemistry of olefin metathesis). ${ }^{36-37}$ This step $(23.8 \mathrm{kcal} / \mathrm{mol})$ can be described as the rate determining step of ROM/RCM reaction (excluding $\mathrm{CH}$-bond activation in the activation and initiation steps, Figure S9, ESI†). (iii) The olefin is released from the rather unstable coordination intermediate 8 (21.0 $\mathrm{kcal} / \mathrm{mol}$ ) to form intermediate 8' (1.0 $\mathrm{kcal} / \mathrm{mol})$. From there, the $c \mathrm{C}_{16}$ double bond inserts into the [W]-hydride $(8$ '-9) forming intermediate 9, which costs $20.1 \mathrm{kcal} / \mathrm{mol}$. The thermodynamically more stable, saturated dimer $c \mathrm{C}_{16}$ is formed by two consecutive hydrogenolysis steps (Figure $\mathrm{S} 9$, ESI†). Side products (other than $\mathrm{cC}_{16}$ ) are formed because, under the applied reaction conditions, DBM occurs (4-9a, 4-9b in Figure 2c, Figure S12, ESI $\dagger$ ) requiring a maximum barrier of around $22 \mathrm{kcal} / \mathrm{mol}$. Starting from 4, with a $C^{8}=C^{9}$ double bond coordinated to the metal, two new coordination intermediates can be formed depending on the direction of the $\mathrm{C}=\mathrm{C}$ insertion into the $\mathrm{W}-\mathrm{H}$ bond: $\mathrm{a}$ 7membered coordination intermediate 6a presenting a $\mathrm{C}^{7}=\mathrm{C}^{8}$ double bond $\left(c_{7}\right.$-pathway in Figure $\left.2 \mathrm{c}\right)$ and a $9^{-}$ membered coordination intermediate $\mathbf{6 b}$, presenting a $\mathrm{C}^{9}=\mathrm{C}^{10}$ double bond $\left(c_{9}\right.$-pathway in Figure $\left.2 \mathrm{c}\right)$. Having obtained four relevant coordination intermediates, we describe the peculiarities of RCM for $c \mathrm{C}_{7^{-}}, c \mathrm{C}_{9^{-}}$, and $c \mathrm{C}_{16}$-productive pathways (6a, $\mathbf{6 b}$ and $\mathbf{6}$, respectively), together with the non-productive $c \mathrm{C}_{8}$-pathway regenerating the starting $c \mathrm{C}_{8}$ from 4 (degenerate alkane metathesis). These pathways are compared in Figure 2c (and Figure S13, ESI†) using again intermediate $\mathbf{5}$ as reference structure at 0.0 $\mathrm{kcal} / \mathrm{mol}$. Visual inspection of Figure $2 \mathrm{c}$ clearly indicates that conversion of $\left[(\equiv \mathrm{SiO}-) \mathrm{W}(=\right.$ carbene $\left.)(\mathrm{Me})_{2}(\mathrm{H})\right] \mathbf{5}$ to $\left[(\equiv \mathrm{SiO}-) \mathrm{W}(=\right.$ carbene $)($ cycloalkyl $\left.)(\mathrm{Me})_{2}\right]$ species $\mathbf{1}, \mathbf{9}$ and $\mathbf{9 a}$ is an exergonic process; conversion to $\mathbf{9 b}$ is an endergonic process. In addition, the stability of $[(\equiv \mathrm{SiO}-) \mathrm{W}(=$ carbene) $($ cycloalkyl $)(\mathrm{Me})_{2}$ ] species, $9 \mathbf{a}>\mathbf{9} \approx \mathbf{1}>\mathbf{9 b}$, is in agreement with the product formation observed under non-confined conditions (Ao) or with supports having large pore sizes (A1). Further, results underline the relevance of ring strain in determining the product distribution (Figure $\mathrm{S}_{4}$, $\mathrm{ESI}+) .{ }^{8}$ Kinetic selectivity between the different pathways is determined at the level of the transition state corresponding to ring-opening of the metallacycle. According to calculations, the $c \mathrm{C}_{7}$-pathway, with a ring opening transition state at $20.5 \mathrm{kcal} / \mathrm{mol}$ is favored, followed by the $\mathrm{cC}_{8^{-}}$ and $c \mathrm{C}_{16-}$ pathways, with a $\mathrm{ROM}$ transition state at 21.6 and $23.8 \mathrm{kcal} / \mathrm{mol}$, respectively. The corresponding transition state for the $c_{9}$-pathway, at $30.7 \mathrm{kcal} / \mathrm{mol}$, is clearly of higher energy, which might explain why the formation of $c \mathrm{C}_{9}$ was experimentally not observed. Intermediate $\mathbf{6 b}$ rather interacts with another $c \mathrm{C}_{8}$-molecule (e.g. leading to $c \mathrm{C}_{17}$ without further DBM) rather than forming $c \mathrm{C}_{9}$ by RCM. Comparing the $c \mathrm{C}_{7}$ - and the $\mathrm{C}_{16}$-pathway, the maximum energy barriers differ by around $3 \mathrm{kcal} / \mathrm{mol}$. Finally, the rather low rate determining barrier of $21.6 \mathrm{kcal} / \mathrm{mol}$ on the $c \mathrm{C}_{8}$-pathway might permit non-productive metathesis leading to the back formation of $c_{8}$, as evidenced in $\mathrm{Ru}^{-}$ catalyzed olefin metathesis metathesis. ${ }^{39-40}$ Hence, the TON determined from the amount of detected (ring contracted and macrocyclic) products seems lower, because it does not include degenerate metathesis.

To rationalize the different product distributions obtained with A1, A2 and $\mathbf{A}_{3}$, we focused on describing the main intermediates on the $c \mathrm{C}_{16}$ - and $c \mathrm{C}_{7}$-pathways, namely 7 and $\mathbf{7 a}$, which are representative for each pathway. To demonstrate that the obtained selectivity originates from a confinement effect, replica exchange Monte Carlo simulations $^{41-42}$ were performed to calculate average effective volume $\left(\mathrm{V}_{\text {eff }}\right)$ and Sterimol shape parameters $\left(\mathrm{L}, \mathrm{B}_{1}\right.$ and $\mathrm{B}_{5}$, $\mathrm{ESI}+)^{17-18}$ of both intermediate.

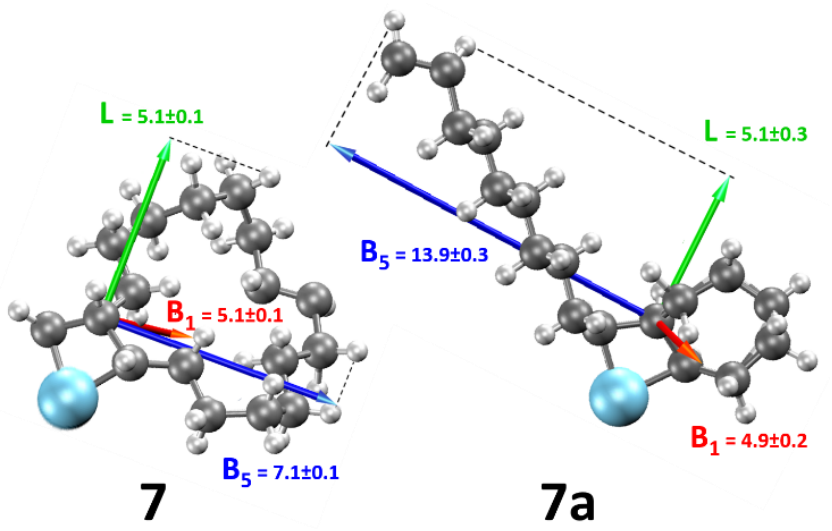

Figure 3. Representation of the Sterimol shape parameters (L, B and $\mathrm{B}_{5}$ ) of intermediates 7 and $\mathbf{7 a}$. L, $\mathrm{B}_{1}$ and $\mathrm{B}_{5}$ values for both intermediates are stated in $\AA$ near the respective axes.

The effective volumes of 7 ( $\left.\underline{V}_{\text {eff: }} 1530 \pm 10 \AA^{3}\right)$ and $7 a\left(V_{\text {eff: }}\right.$ : $1730 \pm 10 \AA 3)$ indicate that the formation of 7 a requires more space than the formation of 7 (Table $\mathrm{S}_{4}$, ESI†) which already supports the hypothesis that confinement effects determine the product distribution. It has been already reported that immobilization of either organic moieties (hybrid materials $)^{43,44}$ or organometallic complexes (SOMC) ${ }^{45}$ inside mesoporous material (as $\mathrm{SBA}_{15}$ and $\mathrm{MCM}_{41}$ ) induces a considerable reduction of the pore size determined by $\mathrm{N}_{2}$ sorption combined with low angle powder X-Ray diffraction. Thus, one has to consider that the actual pore size of $\mathrm{Al}_{1}, \mathrm{~A}_{2}$ and $\mathrm{A}_{3}$ decreases during cyclooctane metathesis, as the pre-catalyst $\mathbf{A}\left[(\equiv \mathrm{SiO}-) \mathrm{WMe}_{5}\right]$ reacts with $c \mathrm{C}_{8}$ to form intermediates as $7,7 \mathbf{a}$ and $\mathbf{5}$. Considering intermediate $\mathbf{5}$, the confinement effect might enhance the formation 
of the cis-isomer of $\mathbf{5}$ facilitating the formation of the dimer $\mathrm{cC}_{16}$. To have a more compelling evidence, we analyzed the Sterimol shape parameters L, $\mathrm{B}_{1}$ and $\mathrm{B}_{5}$ (Figure 3, ESI $\dagger$ ). As expected, the $L$ and $B_{1}$ parameters are quite similar in 7 and 7a, namely L (7: 5.1 $\pm 0.1 \AA$ and 7a: 5.1 $\pm 0.3 \AA)$ and $B_{1}(7: 5.1 \pm 0.3$ $\AA$ and $7 \mathbf{a}: 4.9 \pm 0.2 \AA$ ). Differently, the $B_{5}$ parameter, measuring the maximum size of the system perpendicular to the $\mathrm{L}$ parameter, shows pronounced differences (Figure 3). Specifically, the $B_{5}$ of 7 (bearing a cyclohexadecyl-residue) measures 7.1 $\pm 0.1 \AA$ and indicates that this intermediate is more compact and conformationally rigid than 7 a (bearing a flexible $n$-decenylidene-chain) having a $\mathrm{B}_{5}$ of $13.9 \pm 0.3 \AA$. The clearly larger value of the $B_{5}$ parameter in 7 a relative to 7 strongly supports the hypothesis that the product distribution is determined by confinement effects. Hence, the formation of intermediate $7 \mathbf{a}$ becomes more challenging under confined conditions, because the alkyl-chain might interact with its environment, whereas under non-confined conditions it can move freely. DBM cannot be fully avoided working with the multifunctional catalyst $[(\equiv \mathrm{SiO}$ ) $\left.\mathrm{W}=\mathrm{CH}_{2}(\mathrm{Me})_{2} \mathrm{H}\right] \mathbf{D}$, which can perform ROM-RCM and (de-)hydrogenation at the same time due to (i) the presence of [W]-species on the external surface and (ii) alternative pathways, e.g. through intermediate $\mathbf{G}$.

In conclusion, we found that confinement effects can modulate the product selectivity in $c \mathrm{C}_{8}$ metathesis when $\left[\left(\equiv \mathrm{SiO}_{-}\right) \mathrm{WMe}_{5}\right] \mathbf{A}$ is immobilized inside the mesopores of $\mathrm{MCM}_{41}$. In a confined environment, the formation of ring contracted products (as $c C_{7}$ ) is minimized because the key intermediates along the $c_{7}$-pathway bear flexible alkyl chains which might interact with the environment. Contrary, intermediates along the $\mathrm{cC}_{16}$-pathway are more compact and hence less affected under confined conditions. These results indicate a strategy for designing more selective catalysts by confining bulky transition states and intermediates of unfavourable side products. Works for improving the TON are currently ongoing in our laboratories using bimetallic catalysts. ${ }^{46-47}$

\section{ASSOCIATED CONTENT}

Supporting Information. Experimental and computation details. The Supporting Information is available free of charge on the ACS Publications website.

\section{AUTHOR INFORMATION}

\section{Corresponding Author}

jeanmarie.basset@kaust.edu.sa

luigi.cavallo@kaust.edu.sa

anissa.bendjeriousedjerari@kaust.edu.sa

\section{ACKNOWLEDGMENT}

The research reported in this publication was supported by funding from the King Abdullah University of Science and Technology (KAUST). The authors are grateful to the KAUST Supercomputing Laboratory (KSL) for the resources provided.

\section{REFERENCES}

(1) Derouane, E. G. J. Catal. 1986, 100, 541-544.

(2) Goettmann, F.; Sanchez, C. J. Mater. Chem. 2007, 17, 24-30.

(3) Polarz, S.; Kuschel, A., Chem. Eur. J. 20o8, 14, 9816-9829.

(4) Thomas, J. M.; Raja, R. Acc. Chem. Res. 2008, 41, 708-720.

(5) Li, C. Catal. Rev.-Sci. Eng. 2004, 46, 419-492.

(6) Janda, A.; Vlaisavljevich, B.; Lin, L. C.; Smit, B.; Bell, A. T. J. Am. Chem. Soc. 2016, 138, 4739-56.

(7) Kenmogne, R.; Finiels, A.; Cammarano, C.; Hulea, V.; Fajula, F. J. Catal. 2015, 329, 348-354.

(8) Corma, A. In Zeolite microporous solids: synthesis, structure, and reactivity; Derouane, E. G.; Lemos, F.; Naccache, C.; Ribeiro, F. $R$., eds.; Springer Science \& Business Media 2012; pp 352, 1-611.

(9) Lesthaeghe, D.; Van Speybroeck, V.; Waroquier, M., Phys. Chem. Chem. Phys. 2009, 11, 5222-5226.

(10) Bru, M.; Dehn, R.; Teles, J. H.; Deuerlein, S.; Danz, M.; Mueller, I. B.; Limbach, M. Chem. Eur. J. 2013, 19, 11661-11671.

(11) Basset, J.-M.; Callens, E.; Riache, N. In Handbook of Metathesis, Grubbs, R. H.; Wenzel, A. G. O'Leary, D. J. Khosravi, E., Eds.; Wiley-VCH Verlag GmbH \& Co. KGaA, 2015, pp 33-70.

(12) Basset, J. M.; Coperet, C.; Soulivong, D.; Taoufik, M.; Cazat, J. T., Acc. Chem. Res. 2010, 43, 323-334.

(13) Ahuja, R.; Kundu, S., Goldman, A. S.; Brookhart, M.; Vicente, B. C.; Scott, S. L. Chem. Comm. 2008, 253-255.

(14) Pelletier, J. D. A.; Basset, J. M. Acc. Chem. Res. 2016, 664-677. (15) Huang, Z.; Rolfe, E.; Carson, E. C.; Brookhart, M.; Goldman, A. S.; El-Khalafy, S. H.; MacArthur, A. H. R. Adv. Synth. Catal. 2010, 352, 125-135.

(16) Riache, N.; Callens, E.; Samantaray, M. K.; Kharbatia, N. M.; Atiqullah, M.; Basset, J. M. Chem. Eur. J. 2014, 20, 15089-15094.

(17) Samantaray, M. K.; Dey, R.; Abou-Hamad, E.; Hamieh, A.; Basset, J.-M. Chem. Eur. J. 2015, 21, 6100-6106;

(18) Verloop, A.; Hoogenstraaten, W.; Tipker J. In Development and Application of New Steric Substituent Parameters in Drug Design; Academic Press: New York, 1976; Vol III, 165-207.

(19) Verloop, A. In The Sterimol Approach to Drug Design, Dekker, M., Eds., New York 1987.

(20) Coperet, C.; Chabanas, M.; Saint-Arroman, R. P.; Basset, J. M. Angew. Chem. Int. Ed. 2003, 42, 156-181.

(21) Basset, J.-M.; Psaro, R.; Roberto, D.; Ugo, R., Modern surface organometallic chemistry. John Wiley \& Sons, 2009.

(22) Samantaray, M. K.; Callens, E.; Abou-Hamad, E.; Rossini, A. J.; Widdifield, C. M.; Dey, R.; Emsley, L.; Basset, J. M. J. Am. Chem. Soc. 2014, 136, 1054-1061.

(23) Pump, E.; Viger-Gravel, J.; Abou-Hamad, e.; Samantaray, M.K.; Hamzaoui, .; Gurinov, A.; Anjum, D. H.; Gajan, D.; Lesage, A.; Bendjeriou-Sedjerari, A.; Emsley, L.; Basset, J.-M. Chem. Sci. 2017, 8, 284-29o.

(24) Le Roux, E.; Taoufik, M.; Chabanas, M.; Alcor, D.; Baudouin, A.; Coperet, C.; Thivolle-Cazat, J.; Basset, J. M.; Lesage, A.; Hediger, S.; Emsley, L. Organometallics 2005, 24, 4274-4279.

(25) Le Roux, E.; Taoufik, M.; Copéret, C.; de Mallmann, A.; Thivolle-Cazat, J.; Basset, J.-M.; Maunders, B. M.; Sunley, G. J., Angew. Chem. Int. Ed. 2005, 44, 6755-6758.

(26) Le Roux, E.; Taoufik, M.; Baudouin, A.; Coperet, C.; ThivolleCazat, J.; Basset, J. M.; Maunders, B. M.; Sunley, G. J., Adv. Synth. Catal. 2007, 349, 231-237.

(27) Zhao, D. Y.; Huo, Q. S.; Feng, J. L.; Chmelka, B. F.; Stucky, G. D. J. Am. Chem. Soc. 2014, 136, 10546-10546.

(28) Berenguer-Murcia, A.; Garcia-Martinez, J.; Cazorla-Amoros, D.; Martinez-Alonso, A.; Tascon, J. M. D.; Linares-Solano, A. In Studies in Surface Science and Catalysis 144; Rodriguez-Reinoso, F., McEnaney, B., Rouquerol, J., Unger, K., Eds.; Elsevier Science: Amsterdam, 2002; pp 83-9o.

(29) Choi, S. W.; Bae, H. K. J. Civil Eng. 2014, 18, 1977-1983. (30) Cu, G.; Ong, P. P.; Chu, C. J. Phys. Chem. Solids 1999, 60, 943947. 
(31) Soignier, S.; Taoufik, M.; Le Roux, E.; Saggio, G.; Dablemont, C.; Baudouin, A.; Lefebvre, F.; de Mallmann, A.; Thivolle-Cazat, J.; Basset, J. M.; Sunley, G.; Maunders, B. M. Organometallics 2006, 25, 1569-1577.

(32) Callens, E.; Riache, N.; Talbi, K.; Basset, J. M., Chem. Comm. 2015, 51, 15300-15303.

(33) Bagwe, R. P.; Hilliard, L. R.; Tan, W. Langmuir 2006, 22, 43574362.

(34) Maity, N.; Barman, S.; Callens, E.; Samantaray, M. K.; AbouHamad, E.; Minenkov, Y.; D'Elia, V.; Hoffman, A. S.; Widdifield, C. M.; Cavallo, L.; Gates, B. C.; Basset, J.-M. Chem. Sci. 2016, 7, 1558-1568.

(35) Callens, E.; Abou-Hamad, E.; Riache, N.; Basset, J. M., Chem. Comm. 2014, 50, 3982-3985.

(36) Schrock, R. R. In Alkene Metathesis in Organic Synthesis; Fuerstner, A., ed., Springer, 1998; pp 1-36.

(37) Leconte, M.; Basset, J., J. Am. Chem. Soc. 1979, 101, 7296-7302. (38) Anslyn, E. V.; Dougherty, D. A. In Modern Physical Organic Chemistry, University Science Books, Sausalito, 2oo6, pp. 65-144. (39) Stewart, I. C.; Keitz, B. K.; Kuhn, K. M.; Thomas, R. M.; Grubbs, R. H. J. Am. Chem. Soc. 2010, 132, 8534-8535.
(40).Wenzel, A. G. In Handbook of Metathesis, 2nd ed., Grubbs, R.H., Wenzel, A. G.; O'Leary, D. J.; Khosravi, E., eds.; Wiley-VCH Verlag GmbH \& Co. KGaA: 2015, Vol. 3, pp 253-272.

(41) Sugita, Y.; Okamoto, Y., Chem. Phys. Lett. 1999, 314, 141-151.

(42) Zhou, R. H.; Berne, B. J., Proc. Natl. Acad. Sci. U. S. A. 2002, 99, 12777-12782.

(43) Anwander, R.; Nagl, I.; Widenmeyer, M.; Engelhardt, G.; Groeger, O.; Palm, C.; Röser, T., J. Phys. Chem. B 200o, 104, 35323544 .

(44). Margelefsky, E. L.; Bendjériou, A.; Zeidan, R. K.; Dufaud, V.; Davis, M. E. J. Am. Chem. Soc. 20o8, 130, 13442-13449.

(45) Bendjeriou-Sedjerari, A.; Azzi, J. M.; Abou-Hamad, E.; Anjum, D. H.; Pasha, F. A.; Huang, K. W.; Emsley, L.; Basset, J. M., J. Am. Chem. Soc. 2013, 135, 17943-17951.

(46) Samantaray, M. K.; Dey, R.; Kavitake, S.; Abou-Hamad, E.; Bendjeriou-Sedjerari, A.; Hamieh, A.; Basset, J.-M. J. Am. Chem. Soc. 2016, 138, 8595-8602.

(47) Samantaray, M. K.; Kavitake, S.; Morlanés, N.; Abou-Hamad, E.; Hamieh, A.; Dey, R.; Basset, J.-M., J. Am. Chem. Soc. 2017, 139, 3522-3527. 


1
2
3
4
5
6
7
8
9
10
11
12
13
14
15
16
17
18
19
20
21
22
23
24
25
26
27
28
29
30
31
32
33
34
35
36
37
38
39
40
41
42
43
44
45
46
47
48
49
50
51
52
53
54
55
56
57
50

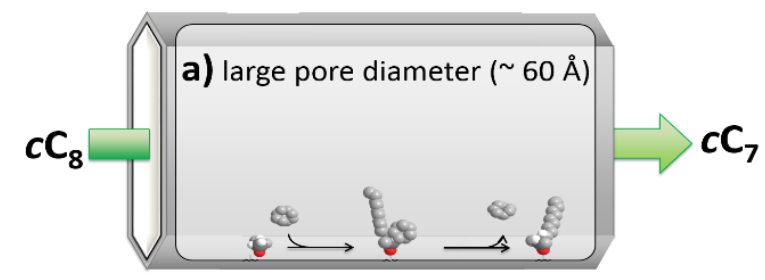

b) small pore diameter $(\sim 25 \AA)$

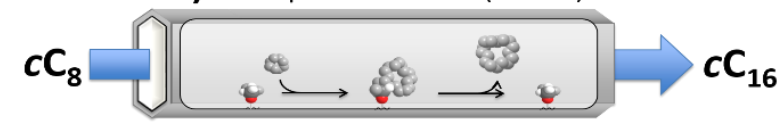

13

14

15

16

17

19

20

21

23

24

25

26

27

28

30

31

32

33

34

35

36

37

38

39

40

41

42

44

45

46

47

48

49

51

52

53

54

55

57

58

59

60 